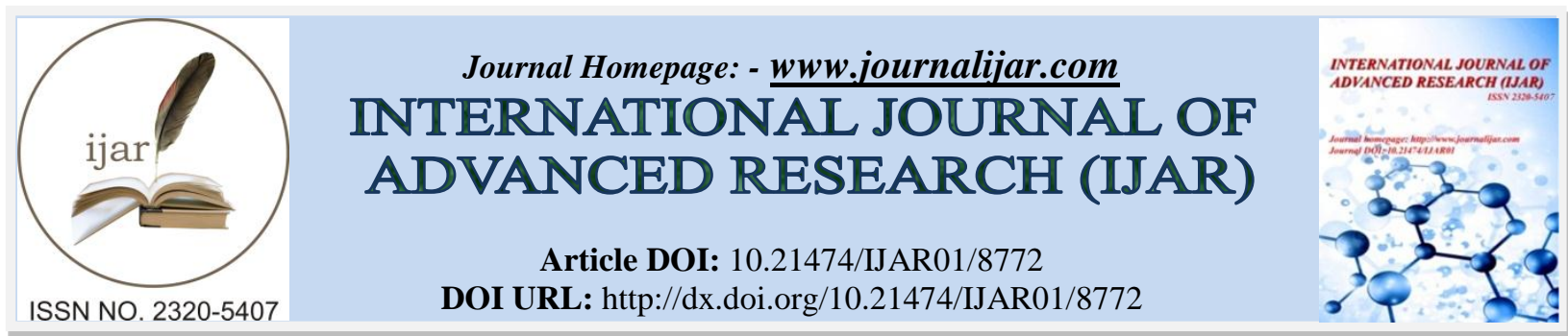

RESEARCH ARTICLE

\title{
IN VITRO EVALUATION OF ESSENTIAL OILS AGAINST RHIZOCTONIA SOLANI (KUHN) THE CAUSAL OF SEEDLING DAMPING OFF DISEASE.
}

El-Wakil D. $A^{1,2}$ and Rania Z. Ahmed ${ }^{3}$.

1. Biology Department, Faculty of Science, Jazan University, Saudi Arabia.

2. Plant Pathology Research Institute, Agricultural Research Centre, Egypt.

3. Kingdom of Saudi Arabia, Jazan University.

\section{Manuscript Info}

\section{Manuscript History}

Received: 20 January 2019

Final Accepted: 22 February 2019

Published: March 2019

Key words:-

Damping off disease, plant essential oils,

$R$. solani, mycelial growth.

\begin{abstract}
Fourteen fungal isolates were isolated from infected tomato roots from Jazan rejion, Southern of Saudi Arabia (KSA) on potato dextrose agar (PDA) medium and corn meal agar (CMA). Among the isolates the most serious soil and seed-borne fungus $R$. solani, wildspread fungus of seedling damping-off disease for many field, horticulture crops alover the world. Five essential oils of different medicinal plants were evaluated for their effect on the suppression of $R$. solani.The oils were Eucalyptus (Eucalyptus globulus), Lemon Tea Tree ( Melaleuca alternifolia), Peppermint ( Mentha piperita),Lemon (Citrus limonum ) and Angelica (Angelica archangelica).A reduction in the mycelium linear growth by increasing the oils concentrations was observed. The tested oils inhibited the mycelium growth of R.solani at different concentrations. Oils at higher concentrations gave an inhibitive effect while lower concentrations had a static action on the mycelial growth. Obtained results clarified that, peppermint (Mentha piperita), and Lemon (Citrus limonum) oils at $2 \%$ caused $100 \%$ suppression of the fungal growth for all tested essential oils.Also, a clear fungistatic effect was recorded at the higher concentrations.
\end{abstract}

Copy Right, IJAR, 2019, All rights reserved.

\section{Introduction:-}

Tomato (Solanum lycopersicum L.), is an important crop around the world. The long growth season, warm weather and humidity available in all regions make these areas suitable for production. These conditions are also favorable to many soil and seed-borne fungal pathogens that reduce tomato yield and profit gain. Tomatoes (Solanum lycopersicum L.) are one of the most popular vegetables in the world and it is grown either in the field or under greenhouse conditions. Tomato production plays a major role in global horticulture, ranking second in the importance of potatoes in many countries. Damping off disease is one of the worst tomato diseases that occur in the nursery and can kill both seed and small seedlings (Stevens et al., 1982). Many fungi that are widely distributed in soil can cause this disease, including Rhizoctonia solani, Pythium spp., Phytophthora spp., Sclerotinia spp. and Fusarium spp. (Agrios, 2005). The elimination of tomato seedlings is the most common disease caused by Rhizoctonia solani (Huang et al., 2011) and Fusarium oxysporum Snyder and Hansen Smith, 2007 as pathogens of soil-borne fungal diseases. $R$. solani develops in both cultured and uncultivated soils and lives in soil in the form of scleroderma and does not generate non-germicidal germs (Mousaa, 2002). Chemical fungicides are often used when the losses caused by $R$. solani are significant. The intensive use of chemical fungicides has not only created 
problems with pesticide resistance and increased soil contamination, but may also have high toxicity to microbial communities. In addition, chemical control is not fully effective, and Rhizoctonia remains a persistent problem (Huang et al., 2011). F. oxysporum was first described more than hundred years ago in the UK causing Fusarium wilt, for the time being, losses from Fusarium wilt can be extremely high in the light of the host host's sensitive malignant host combinations; Losses in Fusarium wilt reach 45\%. In addition, losses from rotten Fusarium in tomatoes was estimated to be as high as 90 and 95\% in Tunisia and Canada, respectively, and 100\% incidence in the field was noticed in the USA (Hibar et al., 2007). Tomato crop has a great market value and it is a good source of vitamins, due to the attack of many diseases transmitted by the soil (soil-borne disease), which cause damage to the quantity and quality of the crop each year. Among the important fungal diseases transmitted by the soil, the disease of seedlings and wilt of adult plants is caused by several types of soil-borne fungi Fusarium spp., Pythium sp., Rhizoctonia solani and Verticillium albo-atrum. (Kaprashvili, 1996; Lucas et al., 1997), and are widely distributed throughout the world. Available literature on this disease indicated that no action has been taken on the disease of inhibition of tomato seedlings.

The purpose of the study was to evaluate the effectiveness of a number of plant essential oils against the serious soil borne fungus R.solani, the most important organism in damping off disease for many field and horticulture crops.

\section{Materials and Methods:- \\ Source of samples:}

Samples of tomato plants (Solanum lycopersicum L.), exhibiting symptoms of damping off disease were collected from different locations in Jazan rejion, and then kept in refrigerator for further studies.

\section{Source of essential oils:}

Pure-grade essential oils of Eucalyptus (Eucalyptus globulus), Lemon Tea Tree ( Melaleuca alternifolia), Peppermint (Mentha piperita)- Lemon (Citrus limonum) and Angelica (Angelica archangelica),were obtained from National Center for Ornamental and Medicinal Resources in Egypt, these essential oils were stored in a dark bottles at $4^{\circ} \mathrm{C}$ for further studies in refregirator.

\section{Frequency of fungi associated with infected plant tissues:}

The isolation and detection of fungi was carried out by following the procedures described by the international rules of organization (ISTA, 2003). The isolated fungi were identified based on their habit characters under stereomicroscope and light microscope and according to key proposed by Barnett and Hunter (2000).

Agar Plate Method ( PDA ):

Infected root tissues of tomato (100 piece ) were surface sterilized with sodium hypochlorite (2.5\%), then washed several times with sterilized water and dried between two folds of filter paper before putting on prepared potato dextrose agar (PDA) for a recovery of the associated fungi. The plates was incubated at $20 \pm 2^{\circ} \mathrm{C}$ for 6 days. The percentage of infected tissues was calculated and the associated fungi were isolated and data was tabulated.

\section{Corn Meal Agar Plate Method (CMA):}

Corn meal Agar ( CMA) Medium: Medium, Active Ingredients corn meal, infusion from 17.0gm/L. and Final pH ( at $25^{\circ} \mathrm{C}$ ) $6.0 \pm 0.2$ were used as culture rich media for fungal growth.

In vitro evaluation of Plant essential oils on mycelia growth of $R$. solani:

From complete covering and growing isolates on petri-dish, a mycelial disc (1-cm diameter) was taken from the periphery of an actively growing agar culture and placed at the center of 9-cm Petri dish containing $15 \mathrm{ml}$ of PDA or CMA. Five essential oils, namely Eucalyptus (Eucalyptus globulus), Lemon Tea Tree ( Melaleuca alternifolia), Peppermint (Mentha piperita) Lemon (Citrus limonum) and Angelica (Angelica archangelica) at different concentrations $(0.5,1.0,1.5$ and $2.0 \%)$ were added and mixed with the PDA medium before it was solidified. The dishes were then quickly sealed with parafilm and incubated at $25^{\circ} \mathrm{C}$. For each treatment, of each compound of the tested concentrations, eight replicates of Petri dish cultures were used. Control treatments consisted of Petri dishes inoculated with the fungus but treated with distilled water instead of a volatile oil. After a 7-day-incubation at $25^{\circ} \mathrm{C}$, the diameters of the fungal colonies was recorded. 
Type of activity of volatile oils (fungistatic or fungicidal) against $R$. solani growth in vitro evaluation:

The aforementioned experiment was repeated once more and treated cultures were observed 7 days of incubation at $25^{\circ} \mathrm{C}$. If no mycelial growth was observed, then Parafilm sealing was removed from the dishes and kept for an additional week under same conditions and the observed for the mycelia growth. Volatile oil was considered fungi static effect when the mycelia grew during the additional incubation period and was considered fungicidal if no mycelial growth was detected.

\section{Statistical Analysis:}

All the analyses described were carried out in 4 replicates and the values expressed as mean standard deviation and standard error. Test of significance was done using Fischer's ' $t$ ' test. Values of $\mathrm{P}<0.05$ were taken as statistically is significant.

\section{Resultrs:-}

Table 1:- Percentage of isolated fungi from tomatos roots using culture media of PDA and CMA

\begin{tabular}{|l|c|c|c|}
\hline \multirow{2}{*}{ Fungi } & \multicolumn{2}{|c|}{ Growing media (\%) } & \multirow{2}{*}{$\begin{array}{c}\text { Mean Percentage } \\
(\%)\end{array}$} \\
\cline { 2 - 3 } & PDA & CMA & 14.5 \\
\hline Aspergillus flavus & 19.0 & 10.0 & 1.5 \\
\hline Aspergillus niger & 3.0 & 0.0 & 8.5 \\
\hline Aspergillus ochraceous & 14.0 & 3.0 & 7.5 \\
\hline Alternaria alternate & 0.0 & 15.0 & 4.5 \\
\hline Cladosporium sp. & 6.0 & 3.0 & 4.5 \\
\hline Fusarium moniliforme & 8.0 & 1.0 & 10.0 \\
\hline Fusarium oxysporum & 13.0 & 7.0 & 3.5 \\
\hline Fusarium solani & 2.0 & 5.0 & 1.5 \\
\hline Fusarium semitectum & 3.0 & 0.0 & 2.0 \\
\hline Penicillium sp. & 16.0 & 4.0 & 5.5 \\
\hline Rhizoctonia solani & 0.0 & 11.0 & 4.0 \\
\hline Mucor sp. & 1.0 & 7.0 & 2.0 \\
\hline Myrothecium sp. & 3.0 & 1.0 & 0.5 \\
\hline Macrophomina phaseolina & 0.0 & 1.0 & 3.0 \\
\hline Others & 6.0 & 0.0 & \\
\hline
\end{tabular}

Fourteen fungal genera were isolated using PDA and CMA medium from tomato roots . Those fungi were Aspergillus flavus, Aspergillus niger, Aspergillus ochraceous, Alternaria alternate, Cladosporium sp., Fusarium moniliforme, Fusarium oxysporum, Fusarium solani, Mucor sp. Macrophomina phaseolina. The highest percentage was recorded on PDA medium with Aspergillus flavus (19.0\%) followed by Penicillium sp.( 16.0\%). On the other hand CMA medium gave different percentages of infections fluctuated from $1.0 \%$ with Macrophomina phaseolina up to $15.0 \%$ with Alternaria alternate.

Table 2:- Effect of plant essential oils (PEO) on mycelial linear growth (mm) of R.solani

\begin{tabular}{|c|c|c|c|c|c|c|c|c|}
\hline \multirow[t]{2}{*}{ Essential oils } & \multicolumn{8}{|c|}{ Mycelia linear growth (mm) / Plant essential oils Concentrations (\%) } \\
\hline & 0.5 & $\begin{array}{c}\% \\
\text { Reduction }\end{array}$ & 1.0 & $\begin{array}{c}\% \\
\text { Reduction }\end{array}$ & 1.5 & $\begin{array}{c}\% \\
\text { Reduction }\end{array}$ & 2.0 & $\begin{array}{c}\% \\
\text { Reduction }\end{array}$ \\
\hline Eucalyptus & $86.2 \mathrm{a}$ & 3.8 & $54.2 \mathrm{~b}$ & 35.8 & $38.5 \mathrm{c}$ & 51.5 & $0.00 \mathrm{~b}$ & 100.0 \\
\hline Lemon Tea Tree & $84.5 \mathrm{a}$ & 5.5 & $47.3 \mathrm{bc}$ & 42.7 & $40.3 c$ & 49.7 & $0.00 \mathrm{~b}$ & 100.0 \\
\hline Peppermint & $80.3 \mathrm{~b}$ & 9.7 & $56.1 \mathrm{~b}$ & 33.9 & $38.5 c$ & 51.5 & $0.00 \mathrm{~b}$ & 100.0 \\
\hline Lemon & $74.0 \mathrm{c}$ & 16.0 & $60.3 c$ & 29.7 & $33.1 \mathrm{c}$ & 56.9 & $0.00 \mathrm{~b}$ & 100.0 \\
\hline Angelica & $77.0 \mathrm{~b}$ & 13.0 & $57.2 \mathrm{c}$ & 32.8 & $27.2 \mathrm{~d}$ & 62.8 & $0.00 \mathrm{~b}$ & 100.0 \\
\hline Control & $90.0 \mathrm{a}$ & 0.0 & $90.0 \mathrm{a}$ & 0.0 & $90.0 \mathrm{a}$ & 0.0 & $90.0 \mathrm{a}$ & 0.0 \\
\hline
\end{tabular}


Values followed by the same letter(s) within a column are not significantly different according to Tukey's range test $(\mathbf{P}=\mathbf{0 . 0 5})$.

Recorded data in Table ( 2 ) concerning estimation the effect of plant essential oils (PEO ) on mycelial linear growth (mm) of the serious fungus R.solani the obtained results showed a different reduction percentages ( \%) with each of the tested oils .In case of conc. $0.5 \%$ with Lemon the reduction percentage was ( $16.0 \%)$,followed by Angelica at $13.0 \%$ but in case of conc. $1.5 \%$ was $62.0 \%$ with Angelica.In case of conc. $2.0 \%$ no mycelial growth was recorded so the the reduction percentage was $(100.0 \%)$.

Table 3:- Determination the type of action of the tested plant essential oils against R.solani. at different Concentrations.

\begin{tabular}{|l|c|c|c|c|c|c|c|c|}
\hline \multirow{2}{*}{ Essential oils } & \multicolumn{9}{|c|}{ Mycelia linear growth (mm) / Plant essential oils Concentrations (\%) } \\
\cline { 2 - 9 } & \multicolumn{9}{|c|}{ Fungicidal } & \multicolumn{5}{c|}{ Fungi-Static. } \\
\cline { 2 - 9 } & $\mathbf{0 . 5}$ & $\mathbf{1 . 0}$ & $\mathbf{1 . 5}$ & $\mathbf{2 . 0}$ & $\mathbf{0 . 5}$ & $\mathbf{1 . 0}$ & $\mathbf{1 . 5}$ & $\mathbf{2 . 0}$ \\
\hline Eucalyptus & - & + & + & + & - & + & - & - \\
\hline Lemon Tea Tree & - & + & + & + & - & + & - & - \\
\hline Peppermint & - & - & - & + & - & + & - & - \\
\hline Lemon & - & + & - & + & - & - & - & - \\
\hline Angelica & - & - & + & + & - & - & - & - \\
\hline Control & nil & nil & nil & nil & nil & nil & nil & nil \\
\hline
\end{tabular}

Control $=$ without essential oils

$(+)$ Positive action $\quad(-)$ Negative action

Tabulated results in Table ( 3 ) showed the type of action of the tested plant essential oils against $R$. solani to detect the effect if it is fungicidal or fungistatic in all tested volatile oils the fungicidal effect was recorded with each of the tested volatile oils specially at high concentrations $2.0 \%$. The fungistatic effect can not be detected only at conc. $1.5 \%$ with Lemon Tea Tree and Peppermint.

\section{Discussion:-}

The present work showed that, plant essential oils proved to be a fungistatic compounds at lower dosages, while at higher concentrations $(1.5$ and $2.0 \%, \mathrm{v} / \mathrm{w})$ against the , they became fungitoxic. Similar results were obtained by (Yanguia, et al.2008), who found that the olive oil can control Rhizoctonia solani and Fusarium solani $100 \%$ inhibition of mycelial growth extracts from Eucalyptus were shown to have fungicidal potential against a large number of soil borne fungi ( Abawi, and Widmer, 2000), El Hadrami, 2004, Bailey, Jiskani,2007 and Lazarovits 2003 ). Peppermint oil has antibacterial and antifungal properties that have secured it a place in the commercial pharmaceutical market (Huang, et.al. 2011). Usually many of essential oils are often fungistatic rather than fungicidal. This means that they inhibit the fungal growth of fungi when they are exposed to the oil (Trillas, 2006 , Leslie, and Summerell, 2006, Samson, et al.2007, Tsioulpas, 2002, Sayadi, S. and. Ellouz 1993 and Ramyabharathi , 2012), Our results in the following study are somewhat similar to these results with some of the tested oils in other research works on essential as reported by ( Weller, et. al. 2002 Samson, et al. 2007). Moreover, even at concentrations that caused lower than $100 \%$ inhibition of mycelial growth, was observed. Samson, et al. ( 2007 ) reported the method to identifiy Aspergilli spp. it is a special tools used to differentiate between different isolates in relation to the effect of essential oils .further work must offered for using essential oils in biocontrol to avoid the risk of pesticides on human health (Ramezani,2002 and Huang et al., 2011). Reduction rate of $R$. solani pathogen was increased by increasing the concentration of essential oils in the growth media. These results are in-agreement with those reported by Yanguia et al.(2008).The obtained results showed that Lemon Tea Tree and Peppermint gave a clear inhibition in mycelial growth and this results are in agreement with that reported by the earlier workers (Ramezani,2002, El-Wakil et al.,2011, Huang et al., 2011 and Barbera et.al.2014 ).

\section{Conflict of interest:}

The authors declare that there is no conflict of interest, regarding this work.

\section{References:-}

1. M.M. Jiskani, M.A. Pathan, K.H. Wagan, M. Imran and H. Abro.(2007).Studies on the control of tomato damping-off disease caused by Rhizoctonia solani (Kuhn). Pak. J. Bot., 39(7): 2749-2754, 2007.

2. Kuprashvili, T.D. (1996). The use phytocides for seed treatment. Zashchita-I- Karantin- Rastenii, 55:31pp. 
3. Lucas, G.B, C.L. Campbell and L.T. Lucas. (1997). Introduction to plant disease identification and management. CBS Pub.and Distributors, New Delhi. 364pp.

4. Stephens, C. T., L. J. Herr and A. F. Schmitthenner. ( 1982). Characterization of Rhizoctonia isolates ssociated with damping-off of bedding plants.Plant Dis., 66: 700-703.

5. Agrios, G. N. (2005). Plant Pathology, 5th Ed. Elsevier Academic Press, San Diego

6. Snyder and Hansen Smith, S. N. (2007). An overview of ecological and habitat aspects in the genus Fusarium with special emphasis on the soil-borne pathogenic forms.Plant Pathol. Bull., 16: 97-120.

7. Huang, X., N. Zhang, X. Yong, X. Yang and Shen Q.(2011). Biocontrol of Rhizoctonia solani dampingoff disease in cucumber with Bacillus pumilus SQR-N43. Microbiol Res., 111167: 135-143.

8. Moussa, T. A. A. (2002). Studies on biological control of sugar beet pathogen Rhizoctonia solani Kühn. Online J. Biol Sci., 2: 800-804.

9. Hibar, K., M. Daami-Remadi and M. El Mahjoub (2007). Induction of resistance in tomato plants against Fusarium oxysporum f. sp. Radicislycopersici by Trichoderma spp. Tunis. J. Plant Prot., 2: 47-58.

10. Barnet, H.L. and B.B. Hunter (2000). Illustrated genera of imperfect fungi.Macmillan Publishing Co., New York.

11. ISTA; International Seed Testing Association (2003). International rules for seed testing. Seed Sci. \& Technol.

12. Yanguia, T., A. Rhoumab, M. A. Trikib, K. Gargouric and J. Bouzida (2008). Control of damping-off caused by Rhizoctonia solani and Fusarium solani using olive mill waste water and some of its indigenous bacterial strains. Crop Protection, 27: 189-197.

13. Abawi, G. S. and T. L. Widmer (2000). Impact of soil health management practices on soil-borne pathogens, nematodes and root diseases of vegetable crops. Appl. Soil Ecol., 15: 37- 47.

14. El Hadrami, A., M. Belaqziz, M. El Hassni, S. Hanifi, A. Abbad, R. Capasso, L. Gianfreda and I. El-Hadrami (2004). Physicochemical characterization and effects of olive oil mill wastewater fertirrigation on the growth of some Mediterranean crops. J. Agron., 3 (4): 247- 254.

15. El-Wakil, D. A. ; H. M. El-Deeb and M. A. Abd-Alla.(2011).Evaluation of some essential oils against the seedborne fungus Sclerotium rollfsii sacc. from peanut seeds . J. Plant Prot. and Path., Mansoura Univ., Vol. 2 (10): $905-917$.

16. Bailey, K. L. and G. Lazarovits. ( 2003). Suppressing soil-borne diseases with residue management and organic amendments. Soil Tillage Res., 72: 169-180.

17. Huang, X., N. Zhang, X. Yong, X. Yang and Shen Q. (2011). Biocontrol of Rhizoctonia solani damping off disease in cucumber with Bacillus pumilus SQR-N43. Microbiol Res., 111167: 135-143.

18. Trillas, M. I., E. Casanova, L. Cotxarrera, J. Ordovas, C. Borrero and M. Avilis 2006. composts from agricultural waste and the Trichoderma asperellum strain T-34 suppress Rhizoctonia solani in cucumber seedlings. Biol. Control,39: 32-38.

19. Samson, R. A., P. Noonim, M. Meijer, J. Houbraken,J. C. Frisvad, J. Varga (2007). Diagnostic tools to identify black Aspergilli. Stud. Mycol.,59: 129-145.

20. Ramyabharathi, S. A., B. Meena and T. Raguchander.( 2012). Induction of chitinase and b-1,3- glucanase PR proteins in tomato through liquid formulated Bacillus subtilis EPCO 16 against Fusarium wilt. J. Today's Biol. Sci. Res. Rev., JTBSRR 1 (1): 50-60.

21. Tsioulpas, A., D. Dimou, D. Ikonomou and G. Aggelis( 2002).Phenolic removal in olive oil mill waste-water by strains of Pleurotus spp. in respect to their phenol oxidase (laccase) activity.Bioresource Technol., 84: 251-257.

22. Leslie, J. F. and B. A. Summerell (2006). The Fusarium laboratory manual. Blackwell Publishing Professional, Hoboken, N.J. p. 212.

23. Sayadi, S. and R. Ellouz (1993). Screening of white rot fungi for the treatment of olive mill wastewater. Chem. Technol. Biotechnol., 57: 141-146.

24. Weller, D. M., J. M. Raaijmakers, B. B. Gardener and L. S. Thomashow (2002). Microbial populations responsible for specific soil suppressiveness to plant pathogens. Annu. Rev. Phytopathol., 40: 309-348.

25. Ramezani, H., H.P. Singh, D.R. Batish, R.K. Kohli and J.S. Dargan. (2002). Fungicidal effect of volatile oils from Eucalyptus citriodora and its major constituent citronellal, New Zealand Plant Protection 55, pp. 327-330.

26. Barbera, A. C., C. Maucieri, A. Ioppolo, M. Milani and V. Cavallaro . (2014).Effects of olive mill waste water Physico-chemical treatments on polyphenol abatement and Italian ryegrass (Lolium multiflorum Lam.) germinability. Water Res., 52: 275-281. 